\title{
A new eremophilane sesquiterpene from the fungus Xylaria sp. V-27 and inhibition activity against degranulation in RBL-2H3 cells
}

\author{
Abdou Tchoukoua ${ }^{1}$, Takuma Suzuki², Nanang Rudianto Ariefta ${ }^{2,3}$, Takuya Koseki ${ }^{2}$, Yusuke Okawa ${ }^{4}$, \\ Ken-ichi Kimura ${ }^{4}$ and Yoshihito Shiono ${ }^{2,3}$ \\ A new eremophilane sesquiterpene, 13,13-dimethoxyintegric acid (1), together with known compound integric acid (2) have \\ been isolated from a fungus, Xylaria sp. V-27, obtained from a dead branch. The structure of 1 was established by means of \\ spectroscopic analyses. 1 and 2 promoted growth restoring activity against the mutant yeast strain (Saccharomyces cerevisiae

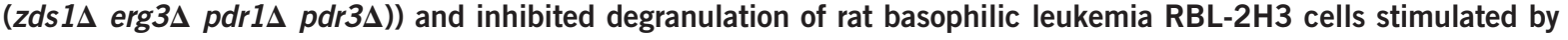 \\ immnunoglobulin G + 2,4-dinitrophenylated-bovine serum albumin (IgE+DNP-BSA), thapsigargin and A23187.
}

The Journal of Antibiotics (2017) 70, 1129-1132; doi:10.1038/ja.2017.120; published online 25 October 2017

Eremophilane sesquiterpenoids are a group of secondary metabolites of both fungi and higher plants. Eremophilane-type sesquiterpene is common in Xylaria species and a lot of sesquiterpenes isolated so far from this genus have demonstrated interesting biological activities such as cytotoxicity, ${ }^{1,2}$ HIV-1 integrase inhibition, ${ }^{3}$ selective ligands for NPY Y5 receptor, ${ }^{4} \alpha$-glucosidase inhibition ${ }^{5}$ and antimalarial activities. ${ }^{6}$ Our previous investigation of fungus Xylaria has led to the isolation of two new eremophilane sesquiterpenes eremoxylarins A (3) and B (4) with antimicrobial ${ }^{7}$ and calcineurin inhibition activities. ${ }^{8}$ In our continuing study of bioactive compounds in this genus, the producing strain was isolated from a dead branch, collected in Yamagata, Japan. This strain was then cultured on the steamed unpolished rice medium for 4 weeks. After cultivation the organic extract was subjected to silica gel and octadecyl silica gel column chromatography to afford a new compound, 13,13-dimethoxyintegric acid (1), and known compound, integric acid (2), as the most abundant constituent of the mycelial extract. We report here the isolation and structural elucidation and biological activities involving anti-allergy of the compounds encountered in this study.

The fungal strain Xylaria sp. V-27 was isolated from a dead branch collected in Yamagata, Japan. This fungus was cultivated on sterile steamed unpolished rice (total $200 \mathrm{~g}$ ) at $25^{\circ} \mathrm{C}$ for 4 weeks. The moldy unpolished rice was extracted with acetone (1.0 1), and acetone extract was concentrated. The resulting aqueous concentrated was partitioned into $n$-hexane layer $(0.31)$, EtOAc layer $(0.51)$ and aqueous layer (0.31). Purifications of eluates were monitored by the characteristic intense blue coloration with $10 \%$ vanillin in $\mathrm{H}_{2} \mathrm{SO}_{4}$ on TLC plates. The EtOAc layer (2.26 g) was chromatographed on a silica gel column with stepwise elution of $n$-hexane-EtOAc (100:0-0:100) and EtOAc/ $\mathrm{MeOH}$ (50:50, 0:100), respectively, to afford fractions $1-1$ to $1-13$. Fraction 1-5 (0.2 g) was rechromatographed on a silica gel column using the stepwise elution $\left(\mathrm{CHCl}_{3}-\mathrm{EtOAc}\right)$ to afford fractions $2-1$ to 2-11. Fractions $2-5$ and 2-6 $\left(\mathrm{CHCl}_{3}-\mathrm{EtOAc}, 40: 60,50: 50,40 \mathrm{mg}\right)$ were further separated by octadecyl silica gel column chromatography eluted with $\mathrm{MeCN}-\mathrm{H}_{2} \mathrm{O}(60: 40)$ to give integric acid (2, $\left.50.0 \mathrm{mg}\right)$ and 13,13-dimethoxyintegric acid (1, $5.5 \mathrm{mg})$.

Compound 2 was determined to be integric acid through the analysis of the spectral data (MS, UV, $[\alpha]_{\mathrm{D}}, \mathrm{IR},{ }^{1} \mathrm{H}$ and $\left.{ }^{13} \mathrm{C} \mathrm{NMR}\right)$ that were indistinguishable from those of integric acid (Figure 1). ${ }^{3}$

Compound 1 was isolated as a white amorphous solid. Its molecular formula was determined to be $\mathrm{C}_{27} \mathrm{H}_{40} \mathrm{O}_{7}$ by high-resolution electrospray ionization MS (HRESIMS). The UV spectrum showed absorption maximum at $223 \mathrm{~nm}$ in $\mathrm{MeOH}$. The IR spectrum exhibited absorption bands at 3356 and $1708 \mathrm{~cm}^{-1}$ that suggested the presence of hydroxy and carbonyl groups. Inspection of ${ }^{1} \mathrm{H}$ and ${ }^{13} \mathrm{C}-\mathrm{NMR}$, DEPT (distortionless enhancement by polarization transfer) and HMQC (heteronuclear multiple quantum correlation) data (Supplementary Figures S1-S5) revealed that 1 contained ester and carbonyl carbons $\left(\delta_{\mathrm{C}} 167.0\right.$ and 198.8$)$, a carboxyl group $\left(\delta_{\mathrm{C}} 178.0\right)$, three olefinic quaternary carbons ( $\delta c 143.2,125.9$ and 158.5), two olefinic methines $\left(\delta_{C} 129.9\right.$ and 149.7$)$, a vinylidene $\left(\delta_{C} 116.5\right)$, an oxymethine $\left(\delta_{\mathrm{H}} 5.50\right.$ and $\left.\delta_{\mathrm{C}} 72.8\right)$, an acetal methine $\left(\delta_{\mathrm{H}} 4.82\right.$ and $\delta_{\mathrm{C}}$ 104.7), an aliphatic quaternary carbon, three methines, six methylenes, two methoxy and four methyl groups (Table 1 ). ${ }^{1} \mathrm{H}-{ }^{1} \mathrm{H}$ COSY and heteronuclear multiple bond correlation (HMBC) (Table 1) spectral data (Supplementary Figures S6 and S7) demonstrated that 1 is

\footnotetext{
${ }^{1}$ Department of Organic Chemistry, Faculty of Science, University of Yaounde I, Yaounde, Cameroon; ${ }^{2}$ Department of Food, Life, and Environmental Science, Faculty of Agriculture, Yamagata University, Yamagata, Japan; ${ }^{3}$ The United Graduate School of Agricultural Sciences, Iwate University, Iwate, Japan and ${ }^{4}$ Graduate School of Agriculture, Iwate University, Iwate, Japan

Correspondence: Professor Y Shiono, Department of Food, Life, and Environmental Science, Faculty of Agriculture, Yamagata University, Tsuruoka, Yamagata 997-8555, Japan. E-mail: yshiono@tds1.tr.yamagata-u.ac.jp

Received 19 April 2017; revised 24 May 2017; accepted 8 June 2017; published online 25 October 2017
} 
<smiles>[2H][C@H]1C[C@]2(C)C(=CC1=O)[C@@H](O)CC[C@H]2C(=O)O</smiles><smiles>C=CC(C)C(OC)O[Mg]</smiles><smiles>C=C(C=O)C(=O)NC(=O)C(C)=CC(C)CCCC</smiles>

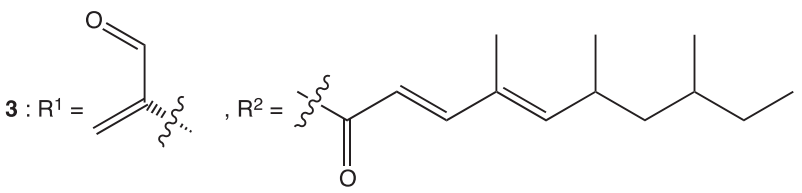

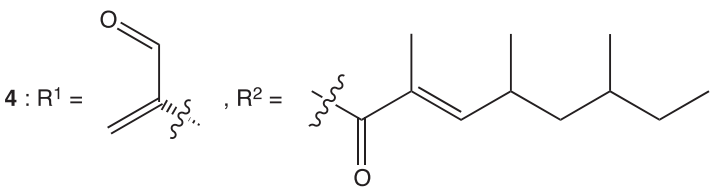

Figure 1 Structures of 13,13-dimethoxyintegric acid (1), integric acid (2) and eremoxylarins $A(3)$ and $B(4)$.

composed of two cyclic sesquiterpene cores attached with a long chain acid through an ester linkage. The decalin moiety of the sesquiterpene was deduced to be an eremophilane based on COSY and HMBC correlations from the methyl proton (Me-14) to quaternary carbons at $\delta_{\mathrm{C}} 38.5(\mathrm{C}-5)$ and $\delta_{\mathrm{C}} 158.5(\mathrm{C}-10)$, methine carbons at $\delta_{\mathrm{C}} 53.6(\mathrm{C}-4)$ and $\delta_{\mathrm{C}} 44.5(\mathrm{C}-6)$, and from a methine proton at $\delta_{\mathrm{H}} 6.04(\mathrm{H}-9)$ to methines at $\delta_{\mathrm{C}} 72.8(\mathrm{C}-1)$ and $\delta_{\mathrm{C}} 45.0(\mathrm{C}-7)$ and a quaternary carbon at $\delta_{\mathrm{C}} 38.5$ (C-5) (Supplementary Figure S7). The COSY and HMBC correlations from Me- $9^{\prime}$ to $\mathrm{C}-1^{\prime}\left(\delta_{\mathrm{C}} 167.0\right)$ and $\mathrm{C}-3^{\prime}\left(\delta_{\mathrm{C}} 149.7\right)$ and from $\mathrm{Me}-10^{\prime}$ to $\mathrm{C}-3^{\prime}$ suggested that there is a 2,4-dimethylocta-2-enoyl moiety in this molecule. Furthermore, the HMBC correlation between $\mathrm{H}-1$ to $\mathrm{C}-1^{\prime}$ and substantial downfield shift for $\mathrm{H}-1$ revealed the location of the octanoyl was at $\mathrm{C}-1\left(\delta_{\mathrm{C}} 72.8\right)$. The configuration of the trisubstituted double bond (C-2' and $3^{\prime}$ ) was assigned as $E$ on the basis of the NOE correlation between $\mathrm{H}-4^{\prime}$ and $\mathrm{Me}-9^{\prime}$ (Supplementary Figure S8). In addition, the HMBC correlation from methine proton at $\delta_{\mathrm{H}} 2.45(\mathrm{H}-4)$ to a carboxyl carbon at $\delta_{\mathrm{C}} 178.0(\mathrm{C}-15)$ established the connectivity of the carboxyl group at $\mathrm{C}-4$. The resemblance in the NMR spectra of 1 (Table 1) and integric acid (2) indicated that 1 was structurally similar to 2 . The major difference was that the aldehyde group in $\mathbf{2}$ was replaced by a dimethoxy methine moiety in $\mathbf{1}$ that was supported by the HMBC correlations from the methoxys at $\delta_{\mathrm{H}} 3.29$ $(\mathrm{H}-16)$ and $3.35(\mathrm{H}-17)$ to the methine at $\delta_{\mathrm{C}} 104.7(\mathrm{C}-13)$. The possibility of 2 being an artifact of 1 produced during the separation could be excluded as 1 was stable for 1 week in $\mathrm{MeOH}$. The relative configurations of C-1, C-4, C-5 and C-7 in 1 were deduced from NOE experiments. NOE correlations from Me-14 to $\mathrm{H}-3^{\prime}$ and from Me-14 to $\mathrm{H}-7$ indicated that Me-14, $\mathrm{H}-7$ and ester side chain moiety at C-1 were all $\beta$-oriented. Furthermore, NOE correlations were observed from $\mathrm{H}-4$ to $\mathrm{H}-2 \mathrm{a}$, suggesting that the carboxylic acid moiety was $\beta$-oriented. This fact is also supported by the similarity between 1 and 2 in the chemical shifts of carbons at C-1, C-4, C-5 and C-7, protons at $\mathrm{H}-1, \mathrm{H}-4, \mathrm{H}-7$ and $\mathrm{H}-14$ and the coupling constants of protons at $\mathrm{H}-4$ and $\mathrm{H}-7$. The relative configuration at $\mathrm{C}-4^{\prime}$ remains uncertain.

The new metabolite reported in this study is a member of the class of eremophilane sesquiterpene and bears close resemblance to integric acid (2) as mentioned above. Compound $\mathbf{1}$ apparently has the same fatty acid as $\mathbf{2}$. Compound $\mathbf{1}$ is the sole reported eremophilane sesquiterpene with 3,3-dimethoxy propene moiety at C-7 of decalin ring (Figure 1). Eremoxylarins A (3) and B (4) that share the same sesquiterpene core as $\mathbf{1}$ and $\mathbf{2}$ but are different in the ester side chain structures have been isolated from fungus in the family Xylariaceae (Figure 1). Eremoxylarins A (3) and B (4) were shown to have restored growth activity against the sensitive mutant yeast strain ( $z d s 1 \Delta$ erg3s pdr1s pdr3s: YNS17 strain) involving $\mathrm{Ca}^{2+}$-signal transduction through the calcinerium inhibition. ${ }^{8}$ Compounds 1 and 2 also gave rise to a faint growth zone around the inhibition zone dose dependently against YNS17 strain $(\mathbf{1} ; 21.3 \mathrm{~mm}, 2 ; 14.9 \mathrm{~mm}$ at $20 \mu \mathrm{g}$ per disc) (Figure 2A) and the phenotypes of 1 and 2 were similar to those observed with 3 and $4 .{ }^{8}$ Compounds 1 and 2 at $10 \mu$ g per disc

\section{Table 1 NMR data of compound $1^{\text {a }}$}

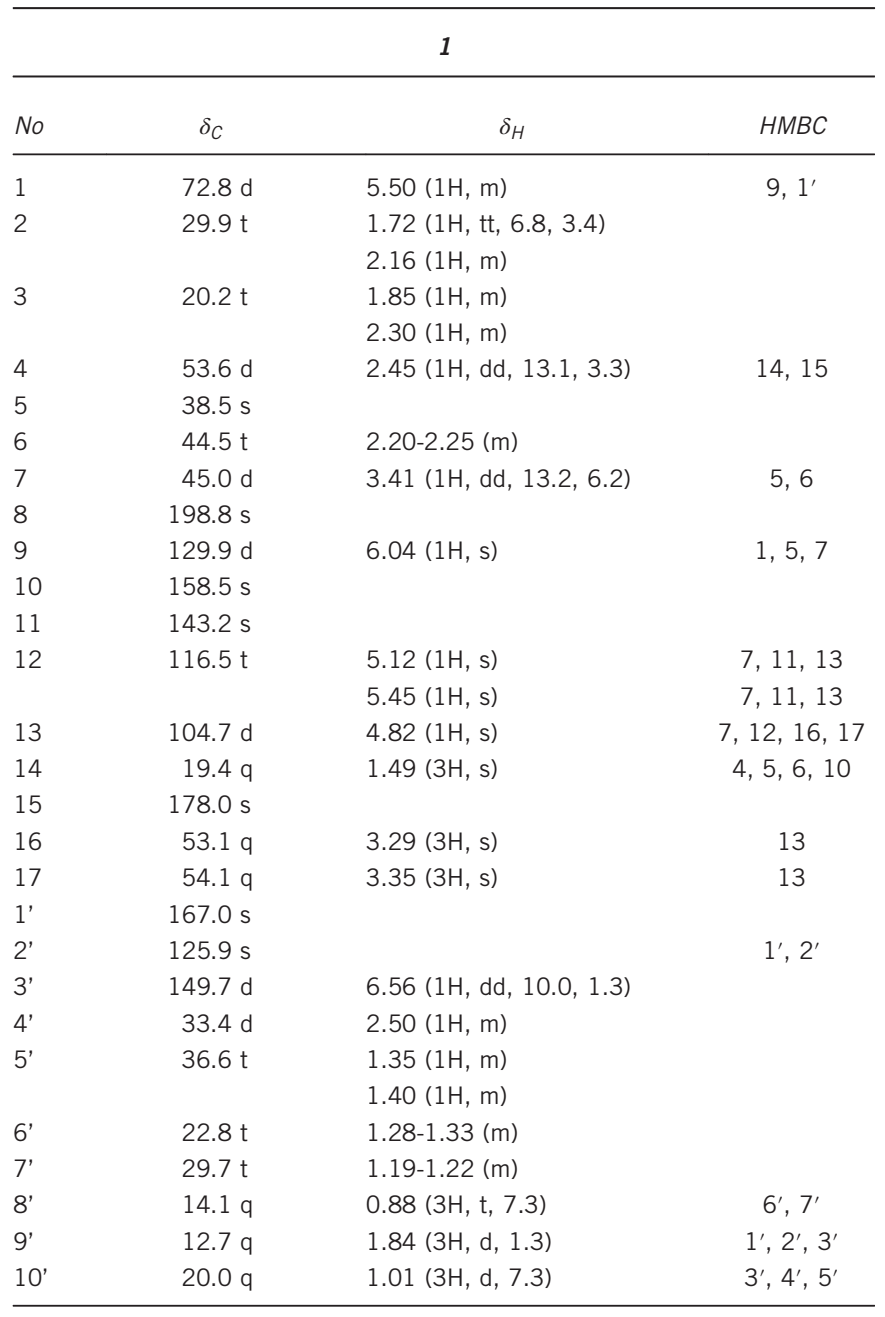

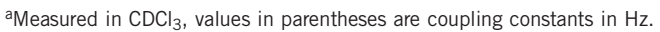


A

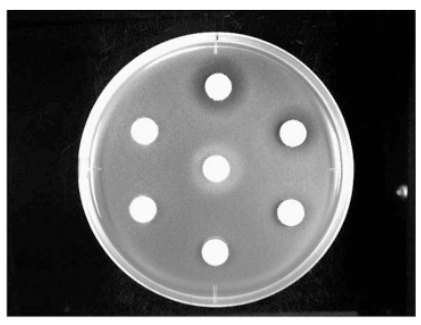

B

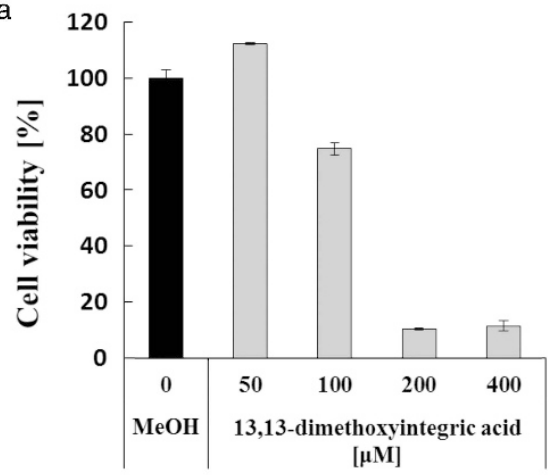

b
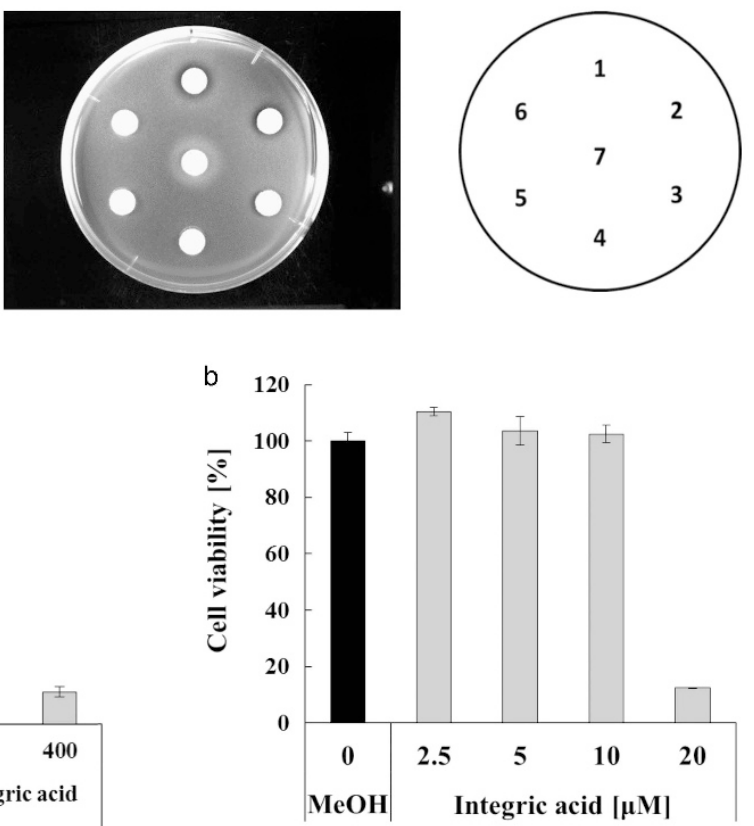

C
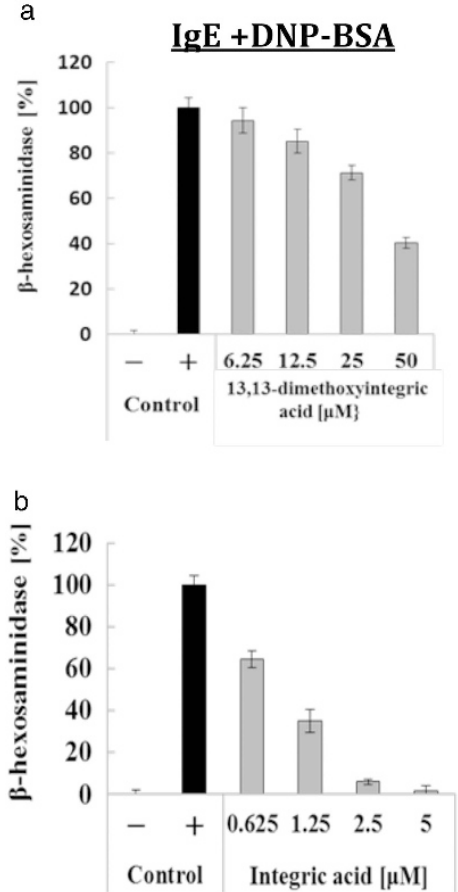

Thapsigargin
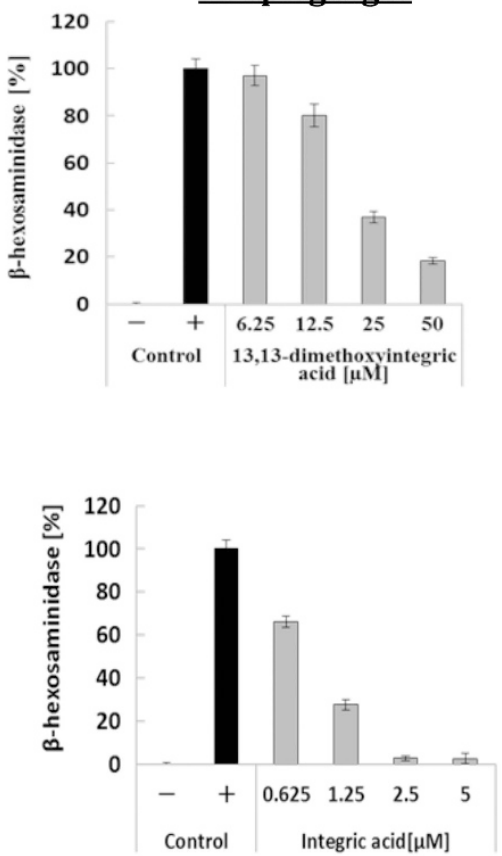

$\underline{A 23187}$
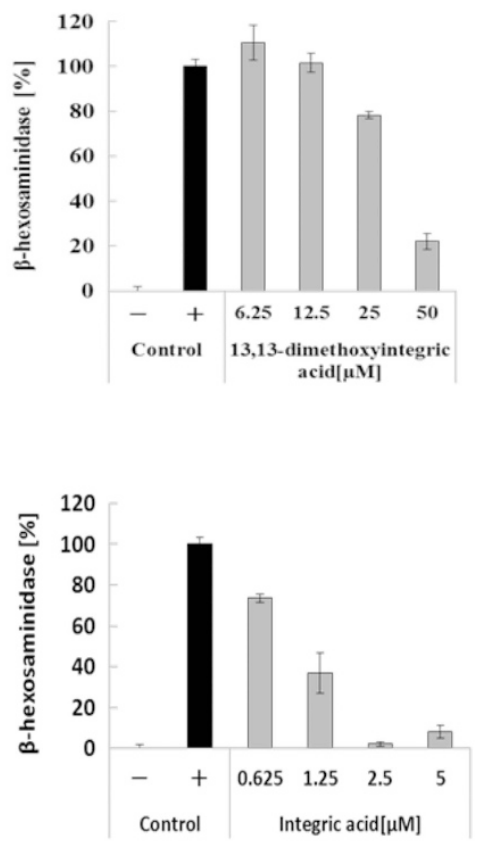

Figure 2 Biological activities of 1 and 2. (A) Restored growth activity of $\mathbf{1}$ (a) and $\mathbf{2}$ (b) against the mutant strain of Saccharomyces cerevisiae (zds $1 \Delta$ erg3د

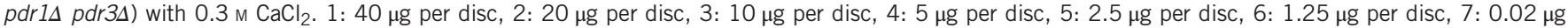
per disc (FK506). (B) Cell viability of RBL-2H3 cells by 1 (a) and 2 (b). Cell viability after $48 \mathrm{~h}$ was determined using the MTT assay. (C) Inhibition of degranulation against RBL-2H3 cells by $\mathbf{1}$ (a) and $\mathbf{2}$ (b). RBL-2H3 cells were sensitized with IgE for $2 \mathrm{~h}$, then added each sample for 30 min and stimulated with DNP-BSA as an antigen for 10 min. RBL-2H3 cells were also stimulated with thapsigargin for 20 min or A23187 for 30 min without sensitization by IgE. The inhibition (\%) of $\beta$-hexosaminidase release by the sample was measured as an absorbance at $405 \mathrm{~nm}$.

(no. 3 in Figure 2A (a and b)) showed the growth restoring zone without the inhibition zone. Mast cells have been widely regarded as the key players of allergic reactions and the rat basophilic leukemia RBL-2H3 cell line is a commonly used $\beta$-hexosaminidase-releasing cell line similar to the mast cell line, although it is derived from basophils.
Elevation of cytosolic $\mathrm{Ca}^{2+}$ levels is a common signal for $\mathrm{RBL}-2 \mathrm{H} 3$ degranulation. Although 1 has a stronger activity of $\sim 4$ times than that of 2 against the mutant yeast, the cytotoxicity of 2 against RBL-2H3 cells $\left(\mathrm{IC}_{50}=15.8 \mu \mathrm{M}\right)$ was $\sim 10$ times stronger than that of $\mathbf{1}$ $\left(\mathrm{IC}_{50}=138.4 \mu \mathrm{M}\right)$ (Figure 2B). Recently, it was reported that the 
growth restoring activity against YNS17 strain was parallel with the inhibition activity of degranulation against RBL-2H3 cells. ${ }^{9}$ Compound 1 inhibited degranulation of RBL-2H3 cells stimulated by IgE + DNP-BSA $\quad\left(\mathrm{IC}_{50}=42.2 \mu \mathrm{M}\right)$, thapsigargin $\quad\left(\mathrm{IC}_{50}=21.2 \mu \mathrm{M}\right)$ and A23187 $\left(\mathrm{IC}_{50}=37.5 \mu \mathrm{M}\right)$, respectively (Figure 2C (a)). Compound 2 inhibited degranulation of RBL-2H3 cells stimulated by IgE+DNPBSA $\left(\mathrm{IC}_{50}=0.92 \mu \mathrm{M}\right)$, thapsigargin $\left(\mathrm{IC}_{50}=0.88 \mu \mathrm{M}\right)$ and $\mathrm{A} 23187$ $\left(\mathrm{IC}_{50}=1.02 \mu \mathrm{M}\right)$, respectively (Figure 2C (b)). These cytotoxic and inhibitory activities of degranulation against RBL-2H3 cells showed that the propenal unit on the structure plays an important role in the activities. Previous evidence has revealed that the propenal moiety is involved in HIV-1 integrase inhibitory activity. ${ }^{3}$ Calcineurin inhibition activity is also paralleled with these activities $\left(1\right.$ : $\mathrm{IC}_{50}=40.5 \mu \mathrm{M}, 2$ : $\left.\mathrm{IC}_{50}=1.2 \mu \mathrm{M}\right) .{ }^{8}$ Otherwise, the dimethoxy moieties in $\mathbf{1}$ may be favorable for the cell permeability of the compound into the mutant yeast than the aldehyde moiety in 2 .

13,13-dimethoxyintegric acid (1): White amorphous powder; $[\alpha]^{20}{ }_{\mathrm{D}}+47.7^{\circ}\left(c\right.$ 0.66, MeOH); UV $(\mathrm{MeOH}) \lambda_{\max }(\log \varepsilon) \mathrm{nm} 223$ (6.58); IR (KBr) $\nu_{\max } 3356,2927,2857,2337,1708,1457,1241,1091$, $991 \mathrm{~cm}^{-1}$; ${ }^{1} \mathrm{H}$ and ${ }^{13} \mathrm{C}$ NMR data, see Table 1; HRESIMS (positive-ion mode) $m / z 499.2665\left([\mathrm{M}+\mathrm{Na}]^{+}\right.$calcd for $\left.\mathrm{C}_{27} \mathrm{H}_{40} \mathrm{O}_{7} \mathrm{Na} 499.2627\right)$.

\section{CONFLICT OF INTEREST}

The authors declare no conflict of interest.

\section{ACKNOWLEDGEMENTS}

AT acknowledges the JSPS RONPAKU (dissertation PhD, ID: R11516)

Program for financial support.

1 McDonald, L. A. et al. 07H239-A, a new cytotoxic eremophilane sesquiterpene from the marine- derived Xylariaceous fungus LL-07H239. J. Nat. Prod. 67, 1565-1567 (2004).

2 Isaka, M., Chinthanom, P., Boonruangprapa, T., Rungjindamai, N. \& Pinruan, U. Eremophilane-type sesquiterpenes from the fungus Xylaria sp. BCC 21097. J. Nat. Prod. 73, 683-687 (2010).

3 Singh, S. B. et al. Structure and absolute stereochemistry of HIV-1 integrase inhibitor integric acid. A novel eremophilane sesquiterpenoid produced by a Xylaria sp. Tetrahedron Lett. 40, 8775-8779 (1999).

4 Smith, C. J. et al. Novel sesquiterpenoids from the fermentation of Xylaria persicaria are selective ligands for the NPY Y5 receptor. J. Org. Chem. 67, 5001-5004 (2002).

5 Song, Y. et al. Four eremophilane sesquiterpenes from the mangrove endophytic fungus Xylaria sp. BL321. Mar. Drugs 10, 340-348 (2012).

6 Isaka, M., Yangchum, A., Supothina, S., Chanthaket, R. \& Srikitikulchai, P. Isopimaranes and eremophilanes from the wood-decay fungus Xylaria allantoidea BCC 23163. Phytochem. Lett. 8, 59-64 (2014).

7 Shiono, Y. \& Murayama, T. New eremophilane-type sesquiterpenoids, eremoxylarins A and B from Xylariaceous endophytic fungus YUA-026. Z. Naturforsch. 60b, 885-890 (2005).

8 Ogasawara, Y., Yoshida, J., Shiono, Y., Miyakawa, T. \& Kimura, K. New eremophilane sesquiterpenoid compounds, eremoxylarins $A$ and $B$ directly inhibit calcineurin in a manner independent of immunophilin. J. Antibiot. 61, 496-502 (2008).

9 Abe, $\mathrm{T}$. et al. Yeast $\mathrm{Ca}^{2+}$-signal transduction inhibitors isolated from Dominican amber prevent the degranulation of RBL-2H3 cells through the inhibition of $\mathrm{Ca}^{2+}$-influx. Fitoterapia 113, 188-194 (2016).

Supplementary Information accompanies the paper on The Journal of Antibiotics website (http://www.nature.com/ja) 